\title{
Adaptive Neuro-Fuzzy Technique for Speed Control of Six-Step Brushless DC Motor
}

\author{
H. Abdelfattah ${ }^{1}$, Mohamed I. Mosaad ${ }^{2}$, Nagwa F. Ibrahim ${ }^{3}$ \\ 1,3 Electrical Department, Faculty of Technology and Education,Suez University,Suez, Egypt \\ ${ }^{2}$ Yanbu Industrial College (YIC), Saudi Arabia, Yanbu Industrial City, 46452, Saudi Arabia
}

\section{Article Info}

\section{Article history:}

Received Jul 13, 2020

Revised Mar 3, 2021

Accepted May 11, 2021

\section{Keyword:}

Adaptive neuro-fuzzy inference system

Six-Step Control

fuzzy logic Control

Brushless DC Motor

\begin{abstract}
Owing to the consistent development in the high energy permanent magnet materials and in the power semiconductors along with control methodologies, permanent magnets brushless DC motors (PM-BLDCs) had been used widely in miscellaneous industrial applications recently. This paper presents an adaptive neuro-fuzzy inference system (ANFIS) controller for a Six-Step BLDC motor drive. This ANFIS controller for BLDC motor drive is used for improving the performance characteristics of the BLDC motor by supporting the profile of the torque, current, speed, and inverter voltages. The effective performance of the proposed ANFIS controller is evaluated through a comparison with the classical proportional-integral-derivative (PID) and Fuzzy controllers. Results disclosed the preeminence of the proposed ANFIS controller over both of the classical PI and Fuzzy controllers. All these simulations are performed using MATLAB/SIMULINK.
\end{abstract}

Copyright $(02021$ Institute of Advanced Engineering and Science. All rights reserved.

\section{Corresponding Author:}

H. Abdelfattah,

Electrical Department, Faculty of Technology and Education,

Suez University,

Suez, Egypt

Email: hany.abdelfattah@suezuni.edu.eg

\section{Nomenclature}

$\begin{array}{ll}\mathrm{u}(\mathrm{t}) & \text { Control action of PID controller } \\ k_{P} & \text { Proportional gain } \\ k_{I} & \text { Integral gain } \\ k_{D} & \text { Derivative gain } \\ e(t) & \text { Error } \\ \mathrm{LP} & \text { large positive number } \\ \mathrm{MP} & \text { medium positive } \\ \mathrm{SP} & \text { small positive } \\ Z & \text { zero value } \\ \mathrm{LN} & \text { large negative } \\ \mathrm{MN} & \text { medium negative } \\ \mathrm{SN} & \text { small negative }\end{array}$

$\begin{array}{ll}i_{a}, i_{b}, i_{c} & \text { Motor phase currents } \\ e_{a}, e_{b}, e_{c} & \text { Motor phase back EMFs } \\ \mathrm{R} & \text { Resistance } \\ \mathrm{Ls} & \text { Self-inductance } \\ \mathrm{M} & \text { Mutual inductance } \\ \mathrm{Kb} & \text { Back emf constant } \\ \mathrm{Tem} & \text { Electromagnetic torque } \\ \mathrm{J} & \text { Moment of inertia } \\ \mathrm{D} & \text { Damping constant } \\ \Omega & \text { Angular speed } \\ \mathrm{Kt} & \text { Torque constant }\end{array}$




\section{INTRODUCTION}

Brushless DC (BLDC) motors are synchronous electrically powered motors; powered by DC electrical current. They are different than DC motors because of their electronic commutation control, instead of the old way of a mechanical commutation system which uses brushes. Nowadays, BLDC motors are widely used in various applications, right from motor vehicles, control and industrial applications to aircraft. The primary reason for increasing such motors' usage can be attributed to good weight/size to power ratio, excellent acceleration performance, little or no maintenance, less acoustic and electrical noise than Brushed DC motors [1]. This has led to significant researches for some control applications of the BLDC motors. Many control schemes were applied to BLDC motors but the PI controller is still the most commonly used one because of its simplicity in installation and construction besides the low cost [2],[3]. There are many problems associated with using classical PI controllers if applied to control the BLDC motors. These problems are represented in the non-linearity in the system and the variation in the operating conditions, such as load variation with its consequences on the motor speed. The non-linearity problem has been addressed using many optimization techniques for optimal tuning of the PI/PID controller parameters [4-6]. Three optimization techniques were presented for optimal tuning of PID controller parameters for BLDC motor speed control, namely particle swarm optimization (PSO) and the Bacterial foraging (BF) technique [11],[12]. The results indicated that the $\mathrm{BF}$ technique was more efficient and effective than PSO.

The second problem appears even with the optimal tuning of PI/PID controller parameters. The optimization is not guaranteed except at the operating conditions at which the parameters were optimally tuned. This calls for on-line tuning of the PI/PID controller parameters, which is hard to be achieved as the long time taken by the optimization techniques to optimally tuning the PI/PID controller parameters [4]. To solve this issue, many adaptive control schemes were applied for example but not limited to artificial neural network [5], model predictive control [6], model-free adaptive control [7], and adaptive-network-based fuzzy inference system (ANFIS), [16-18].

R. Kandiban, R. Arulmozhiyal suggested an improved adaptive Fuzzy PID controller for BLDC motor speed control as in [9]. The simulation and experimental results show that the Fuzzy logic controller [10] effectively and efficiently controls the BLDC. The comparison between the fuzzy controller and PI controller is presented for speed control of BLDC motor using MATLAB simulation as in [13]. A neuro Fuzzy controller was tested for BLDC motor speed control with good performance as given in [14],[15]. ANFIS was used for speed control of BLDC motor as in [16]. This study showed the BLDC motor speed profile only during constant and variable loads without offering any other profiles for the electromagnetic torque, stator current and voltages. Another survey of speed control of BLDC motor with ANFIS controller was presented. The torques and inverter voltages waveforms were investigated only, without addressing the stator currents, which is an important issue when studying such motor control methods [17]. The performance of the ANFIS controller for BLDC motor speed control with investigating speed, voltage and current were given in [18] but without introducing any other control methodology to assess the proposed control method (ANFIS).

This paper presents an ANFIS controller for adjusting the speed of a BLDC motor. Besides improving the motor speed profile, the ANFIS controller also improved the motor currents and electromagnetic torque. The improved ANFIS controller proposed in this paper is compared to the other two control methods: classical PI controller and fuzzy controller. The ANFIS controller showed better performance than the two other controllers by comparing some control indices including maximum overshoot and the settling time.

The rest of this paper is sorted out as follows: Section 2 gives a short portrayal and numerical plan of the Six-Step BLDC motor drive operating principle and model equations. In Section 3 the PID controller is explained. The idea of Fuzzy control system is discussed in section 4. The concept of (ANFIS) is illustrated in section 5. The results and discussions are in section 6. Finally, the conclusion of the research is in Section 7.

\section{BLDC MOTOR OPERATING PRINCIPLE AND MODEL}

The brush-commutator arrangement has several disadvantages, including sparking and wearing out of the arrangement components. At the same time, the electronic one is characterized by the absence of brushes. Therefore, these problems do not exist, which is one of the essential advantages of using electroniccommutation. BLDC motors are permanent synchronous machines with rotor position feedback. The brushless motors are generally controlled using a three-phase power semiconductor bridge. The motor requires a rotor position sensor for starting and providing a proper commutation sequence to turn on the power switches in the inverter bridge. Based on the rotor position, the switches are commutated sequentially every 60 degrees. Instead of commutating the armature current using brushes, electronic commutation is used [19]. 


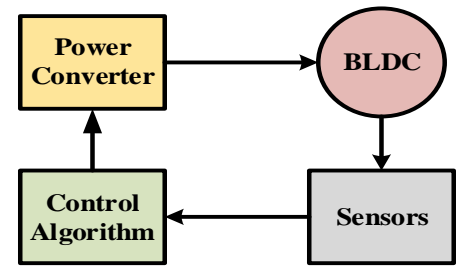

Figure 1. Basic block diagram of BLDC motor

The block diagram of the BLDC motor is shown figure 1. The BLDC motor consists of four main parts include power converter, permanent magnet-synchronous machine (PMSM), sensors and control algorithm. The power converter transforms power from the source to the PMSM, which converts the electrical energy to mechanical energy. The rotor position sensors have great importance and effects on the operation of BLDC motors. These sensors and the command control signals affect the motor performance through torque, voltage and speed commands. The control algorithms used for BLDC motors drive the gate signal of the power electronic switches and consequently improve the motor performance.

Mainly there are two control algorithms for BLDC motor control, namely voltage source-based drives and current source-based drives. Both of these control algorithms were used in a permanent magnet synchronous machine with either sinusoidal or non-sinusoidal back emf waveforms. The Machines with sinusoidal back emf, shown in figure 2 may be controlled to achieve nearly constant torque. However, a machine with a non-sinusoidal back emf, figure 3 reduces the inverter sizes and reduces the losses for the same power level [15],[16].

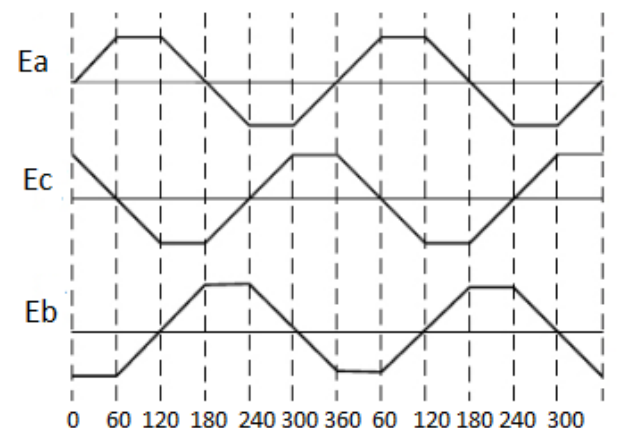

Figure 2. Trapezoidal back emf of three-phase BLDC motor

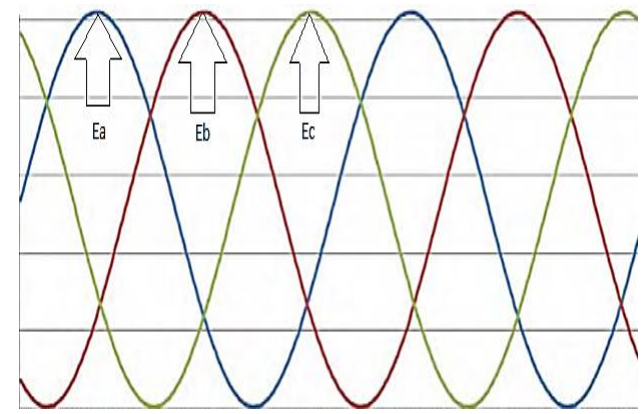

Figure 3. Sinusoidal phase back emf of BLDC motor

The BLDC motor is fitted with a rotor magnet and three stator windings. Rotor-driven currents may be neglected due to the magnets' high resistivity and stainless steel [8]. The motor voltage equations can be given as [19]:

$$
\begin{aligned}
& \mathrm{V}_{\mathrm{a}}=\mathrm{i}_{\mathrm{a}} \mathrm{R}_{\mathrm{a}}+\mathrm{L}_{\mathrm{a}} \frac{\mathrm{dia}}{\mathrm{dt}}+\mathrm{M}_{\mathrm{ab}} \frac{\mathrm{dib}}{\mathrm{dt}}+\mathrm{M}_{\mathrm{ac}} \frac{\mathrm{dic}}{\mathrm{dt}}+\mathrm{e}_{\mathrm{a}} \\
& \mathrm{V}_{\mathrm{b}}=\mathrm{i}_{\mathrm{b}} \mathrm{R}_{\mathrm{b}}+\mathrm{L}_{\mathrm{b}} \frac{\mathrm{dib}}{\mathrm{dt}}+\mathrm{M}_{\mathrm{ba}} \frac{\mathrm{dia}}{\mathrm{dt}}+\mathrm{M}_{\mathrm{bc}} \frac{\mathrm{dic}}{\mathrm{dt}}+\mathrm{e}_{\mathrm{b}}
\end{aligned}
$$




$$
\mathrm{V}_{\mathrm{c}}=\mathrm{i}_{\mathrm{c}} \mathrm{R}_{\mathrm{c}}+\mathrm{L}_{\mathrm{c}} \frac{\mathrm{dic}}{\mathrm{dt}}+\mathrm{M}_{\mathrm{ca}} \frac{\mathrm{dia}}{\mathrm{dt}}+\mathrm{M}_{\mathrm{cb}} \frac{\mathrm{dib}}{\mathrm{dt}}+\mathrm{e}_{\mathrm{c}}
$$

where $e_{a}, e_{b}$ and $e_{c}$ are the back emfs which are functions of rotor angle that is given by

$$
\mathrm{e}=\mathrm{K}_{\mathrm{b}} \omega_{\mathrm{m}}
$$

where $\mathrm{Kb}$ is the back emf constant.

These voltage equations can be formulated in a matrix form as:

$$
\left[\begin{array}{c}
\mathrm{V}_{\mathrm{a}} \\
\mathrm{V}_{\mathrm{b}} \\
\mathrm{V}_{\mathrm{C}}
\end{array}\right]=\left[\begin{array}{ccc}
\mathrm{L}_{\mathrm{a}} & \mathrm{M}_{\mathrm{ab}} & \mathrm{M}_{\mathrm{ac}} \\
\mathrm{M}_{\mathrm{ba}} & \mathrm{L}_{\mathrm{b}} & \mathrm{M}_{\mathrm{bc}} \\
\mathrm{M}_{\mathrm{ca}} & \mathrm{M}_{\mathrm{cb}} & \mathrm{L}_{\mathrm{c}}
\end{array}\right] \frac{\mathrm{d}}{\mathrm{dt}}\left[\begin{array}{c}
\mathrm{i}_{\mathrm{a}} \\
\mathrm{i}_{\mathrm{b}} \\
\mathrm{i}_{\mathrm{c}}
\end{array}\right]+\left[\begin{array}{ccc}
\mathrm{R}_{\mathrm{a}} & 0 & 0 \\
0 & \mathrm{R}_{\mathrm{b}} & 0 \\
0 & 0 & \mathrm{R}_{\mathrm{c}}
\end{array}\right]\left[\begin{array}{c}
\mathrm{i}_{\mathrm{a}} \\
\mathrm{i}_{\mathrm{b}} \\
\mathrm{i}_{\mathrm{c}}
\end{array}\right]+\left[\begin{array}{c}
\mathrm{e}_{\mathrm{a}} \\
\mathrm{e}_{\mathrm{b}} \\
\mathrm{e}_{\mathrm{c}}
\end{array}\right]
$$

Since there is no saliency, self-inductance is independent of the rotor position. Therefore,

And mutual inductances

$$
L_{a}=L_{b}=L_{c}=L
$$

$$
M_{a b}=M_{b a}=M_{b c}=M_{c b}=M_{a c}=M_{c a}=M
$$

For a balanced three phase system, phase resistances are equal, i.e.,

$$
R_{a}=R_{b}=R_{c}
$$

The matrix form of the three-phase voltages given in (5) can be updated based on the assumptions (6-8) as :

$$
\left[\begin{array}{l}
V_{a} \\
V_{b} \\
V_{C}
\end{array}\right]=\left[\begin{array}{ccc}
L & M & M \\
M & L & M \\
M & M & L
\end{array}\right] \frac{d}{d t}\left[\begin{array}{l}
i_{a} \\
i_{b} \\
i_{c}
\end{array}\right]+\left[\begin{array}{ccc}
R & 0 & 0 \\
0 & R & 0 \\
0 & 0 & R
\end{array}\right]\left[\begin{array}{c}
i_{a} \\
i_{b} \\
i_{c}
\end{array}\right]+\left[\begin{array}{c}
e_{a} \\
e_{b} \\
e_{c}
\end{array}\right]
$$

The electromagnetic torque can be expressed as:

$$
T_{e m}=j \cdot \frac{d \omega r}{d t}+D \omega r+T_{l}
$$

Where the electromagnetic torque depends upon back emf and rotor current and can be expressed as:

$$
T_{e m}=\frac{1}{\omega_{m}\left[e_{a} i_{a}+e_{b} i_{b}+e_{c} i_{c}\right]}
$$

From the above equations, the transfer function can be deduced to be as follows:

$$
G(s)=\frac{\omega(s)}{V(s)}=\frac{K_{t}}{\left[\left(L_{s}+R\right)(J s+D)+K_{t} K_{b}\right]}
$$

In the BLDC motor is fed a PWM inverter. Decoding the signals from the Hall effect produces signals from the inverter gates. It is based on the use of 6 different steps according to an angle of $60 \mathrm{o}$ electrical rotation. The term trapezoidal refers to the current waveform and the form of the back electromotive force that is produced by this process. Nevertheless, the 6-step algorithm is based on sensing the rotor's position using three hall sensors that are mounted in the drive motor. These hall sensors are installed every $120^{\circ}$, six separate commutations are possible with these sensors, and phase switching depends on the values of the hall sensors. The chart of these steps are shown in figure 4. 


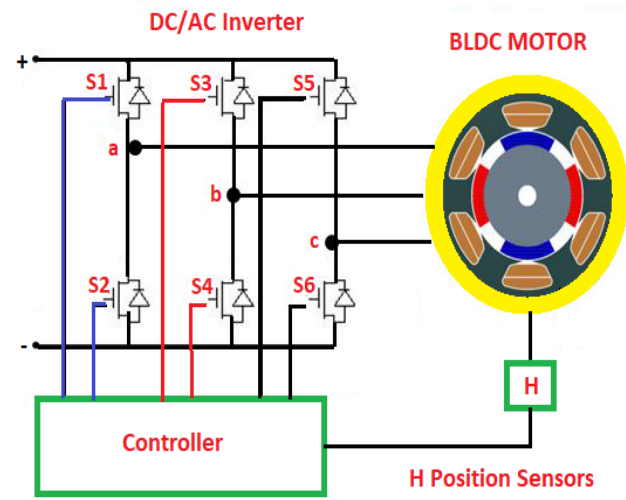

Figure 4. Schematic of Six-Step Commutation model

Designing an appropriate and applicable controller for any process is an important and vital issue to overcome any error and reach the desired target at minimum time.This paper introduces a speed control of BLDC motor using three different controllers, PID,Fuzzy and ANFIS.

\section{PID CONTROLLER}

PID controller is used in this paper as a benchmark controller [2-4] to test the ANFIS proposed controller's effectiveness. The first step is to measure the actual speed of the BLDC motor (wa). This actual speed is compared to the reference speed (wd) which is assumed to be $3000 \mathrm{rpm}$. The error between these two speeds is used to stimulate the PID controller to generate the control signal used to generate the inverter gate pulses. The PID controller for the speed control of BLDC motor is shown in figure 5-a. The error between the reference and the actual motor speeds can be defined as:

$$
e(t)=\omega d(t)-\omega a(t)
$$

Then the control signal $(\mathrm{u}(\mathrm{t}))$ is defined as:

$$
u(t)=k_{P} e(t)+k_{I} \int_{0}^{t} e(t) d(t)+k_{D} \frac{d e(t)}{d t}
$$

\section{FUZZY LOGIC CONTROLLER}

The Fuzzy Logic controller's basic components are a knowledge base, fuzzification, inference engine, and interface for defuzzification. In the Fuzzy logic controller, the addition of fuzziness to data is called fuzzification. Fuzzy linguistic definitions are formal device representations made by fuzzy rules of the IF-THEN. This process for the Fuzzy Controller is updated to keep the motor speed at $3000 \mathrm{rpm}$. The Fuzzy controller block diagram is shown in figure $5-\mathrm{b}$

\section{ADAPTIVE NEURO-FUZZY INFERNRCE CONTROLLER}

The ANFIS technique is simply constructing an input-output network depending on feed-forward learning techniques; its construction consists of nodes and links connecting these nodes. All of them are adaptive targeting to minimize error as possible by learning [13]. ANFIS lets linguistic and numerical data be combined. The neuro-fuzzy systems can acquire numerical knowledge of fuzzy, by comparison. Inside the adaptive neuro-fuzzy model, two basic learning algorithms are required. One is the structural learning algorithm to find suitable fuzzy logic rules and the second is the learning parameter algorithm to change the membership functions and other parameters according to the output of the target system [13]. Training algorithms of gradient-descent from the neural network field are used in this analysis. The approach is usually expressed as modeling Neuro-Fuzzy. Under the Takagi-Sugeno (TS) model, two fuzzy if-then rules are given as follows for communication of the ANFIS structure:

Rule 1: If ( $\mathrm{x}$ is $\mathrm{A} 1)$ and $(\mathrm{y}$ is $\mathrm{B} 1)$ then $\mathrm{f} 1=\mathrm{p} 1 \mathrm{x}+\mathrm{q} 1 \mathrm{y}+\mathrm{r} 1$

Rule 2: If ( $x$ is $A 2)$ and ( $y$ is B2) then $f 2=p 2 x+q 2 y+r 2$

Here, ri, pi and qi are the design parameters determined during the period of training phase.

IJEEI, Vol. 9, No. 2, June 2021: $302-312$ 
ANFIS controller system's general block diagram designed for a fuzzy controller is shown in figure5-c. The ANFIS controller method uses a multi-iteration testing technique and a hybrid learning algorithm.

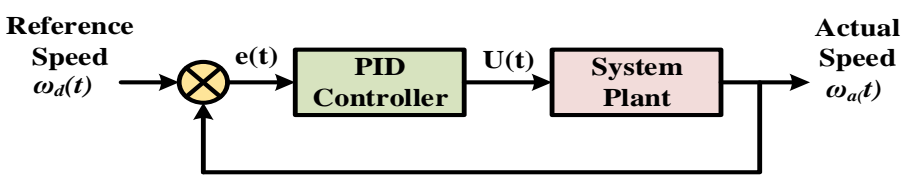

(a)

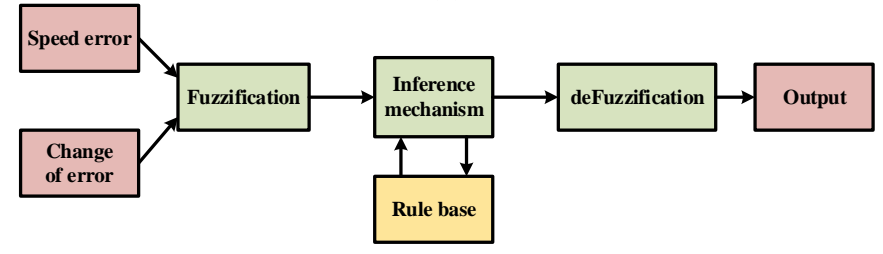

(b)

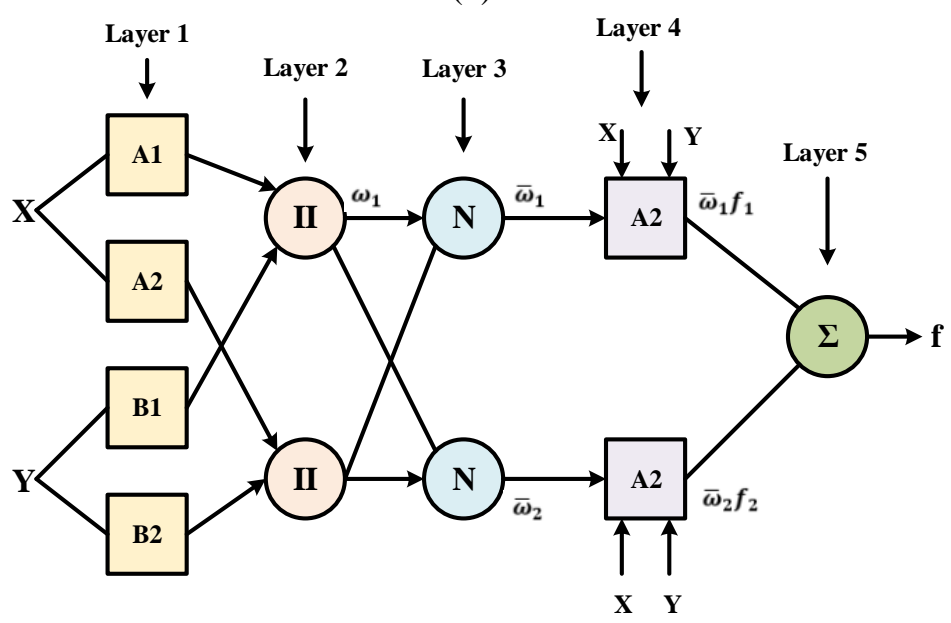

(c)

Figure 5. Block diagrams for the three controllers proposed (a) PID Controller (b) Fuzzy Controller (c) ANFIS controller system

all adjustable parameters (weights and membership functions) are changed by ANFIS' learning or training algorithm to compare ANFIS output to trained data. The output of Fuzzy system z in eq (15).

$$
\begin{gathered}
z=\frac{w_{1}}{w_{2}+w_{1}} z_{1}+\frac{w_{2}}{w_{1}+w_{2}} z_{2} \\
=\overline{w_{1}}\left(p_{1} x+q_{1} y+r_{1}\right)+\overline{w_{2}}\left(p_{2} x+q_{1} y+r_{2}\right) \\
=\left(\overline{w_{1}} x\right) p_{1}+\left(\overline{w_{1}} y\right) q_{1}+\left(\overline{w_{1}}\right) r_{1}+\left(\overline{w_{2}} x\right) p_{2}+\left(\overline{w_{2}} y\right) q_{2}+\left(\overline{w_{2}}\right) r_{2}
\end{gathered}
$$

Nevertheless, if membership function parameters are not set and require adjustment, the area to be trained becomes wider, and convergence of the training algorithm slows down. In such cases, the hybrid learning algorithm with gradient descent and least-squares gives more effective results. The neuro-fuzzy block diagram of BLDC motor shows in figure 6.

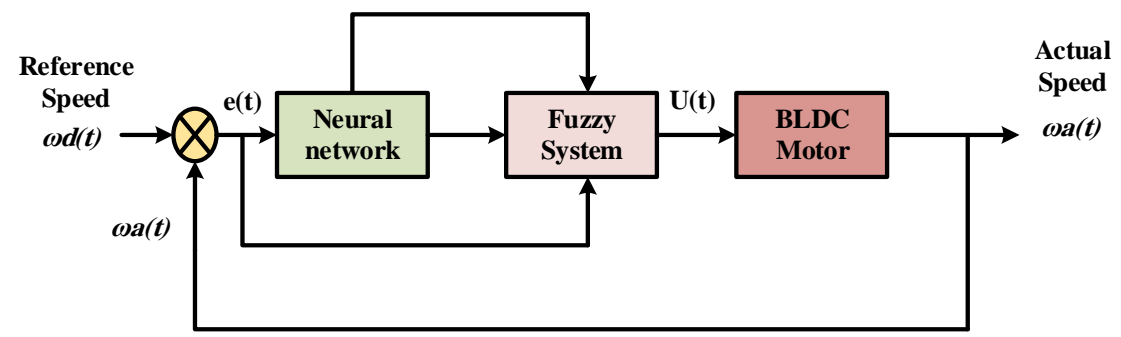

Figure 6. Block diagram of Neuro-Fuzzy Controller 


\section{RESULTS AND DISCUSSIONS}

This paper introduces speed control of BLDC motor using ANFIS. The proposed ANFIS controller's performance is compared to the other two controllers, PID and Fuzzy controllers. In this paper, a Six-Step BLDC Motor is utilized along with the controllers and simulated in MATLAB/SIMULINK. The various parameters used for simulation are listed in Table 3 in the Appendix.

\section{- PID Controller}

Most industrial applications use PID Controller because its ease of usage and simplicity of tuning parameters at the value make the system unstable. The used coefficients for our controller after many trials with the try and error method and Ziegler Nichols method are $\mathrm{KP}=0.0017, \mathrm{KI}=027$, and $\mathrm{KD}=0$.

\section{- Fuzzy Controller}

The error and derivative error of speed are used as the two inputs. Membership functions of input and output variables have been shown in figures 7 (a),(b). The base rules of the obtained fuzzy inference system consist of 49 rules. The fuzzy rules are as shown in table 1.

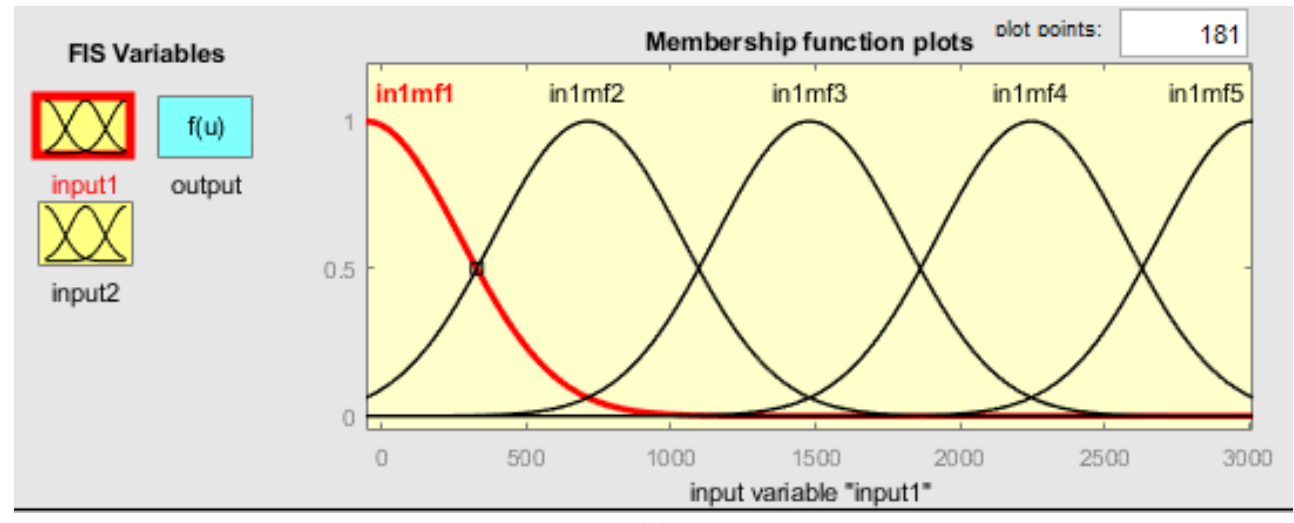

(a)

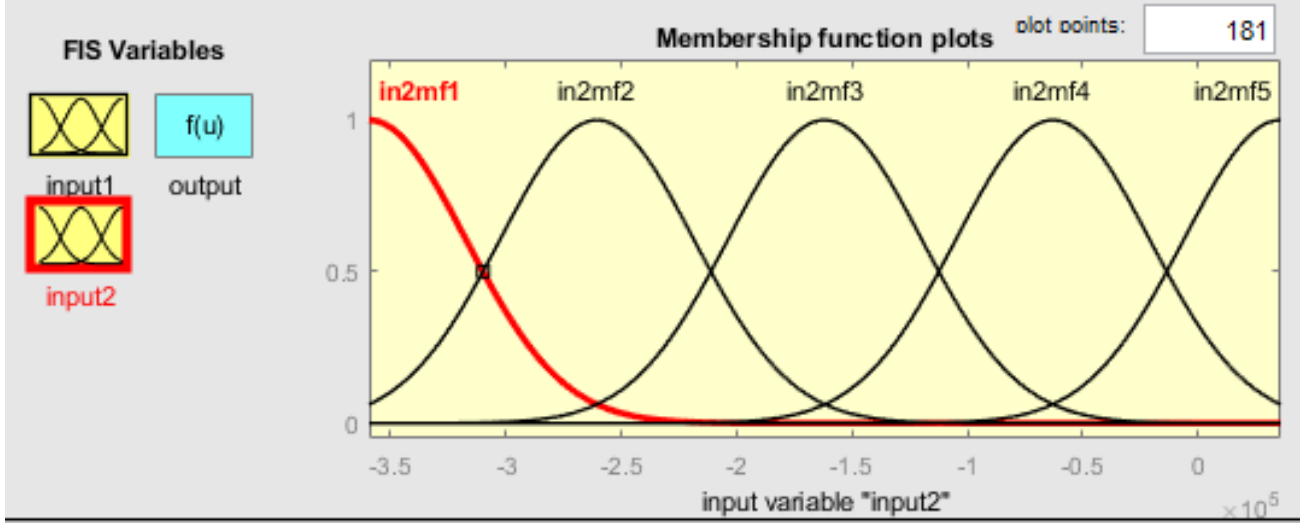

(b)

Figure 7. Membership functions for the speed error input (a) speed error input (b) dervative of the speed error input

Table 1. Fuzzy Rules Matrix

\begin{tabular}{cccccccc}
\hline $\mathbf{E}$ & $\mathbf{L P}$ & $\mathbf{M P}$ & $\mathbf{S P}$ & $\mathbf{Z}$ & $\mathbf{S N}$ & MN & LN \\
$\mathbf{d E}$ & & & & & & \\
\hline LP & LP & LP & LP & LP & MP & SP & Z \\
MP & LP & LP & LP & MP & SP & Z & SN \\
SP & LP & LP & MP & SP & Z & SN & MN \\
Z & LP & MP & SP & Z & SN & MN & LN \\
SN & MP & SP & Z & SN & MN & LN & LN \\
MN & SP & Z & SN & MN & LN & LN & LN \\
LN & Z & SN & MN & LN & LN & LN & LN \\
\hline
\end{tabular}




\section{- ANFIS Controller}

As usual at any industry application, more effective performance with the fastest response is required, so it was the start of using some intelligent techniques depends on learning like Neuro Fuzzy techniques specially ANFIS (Adaptive Neuro Fuzzy Inference system) which also depends on Fuzzy logic controller and integrating these rules of fuzzy in neural network to make it learning in the system and to improve its performance very fast. The simulation structure of adaptive neuro-fuzzy system with MATLAB is shown in figure 8 .

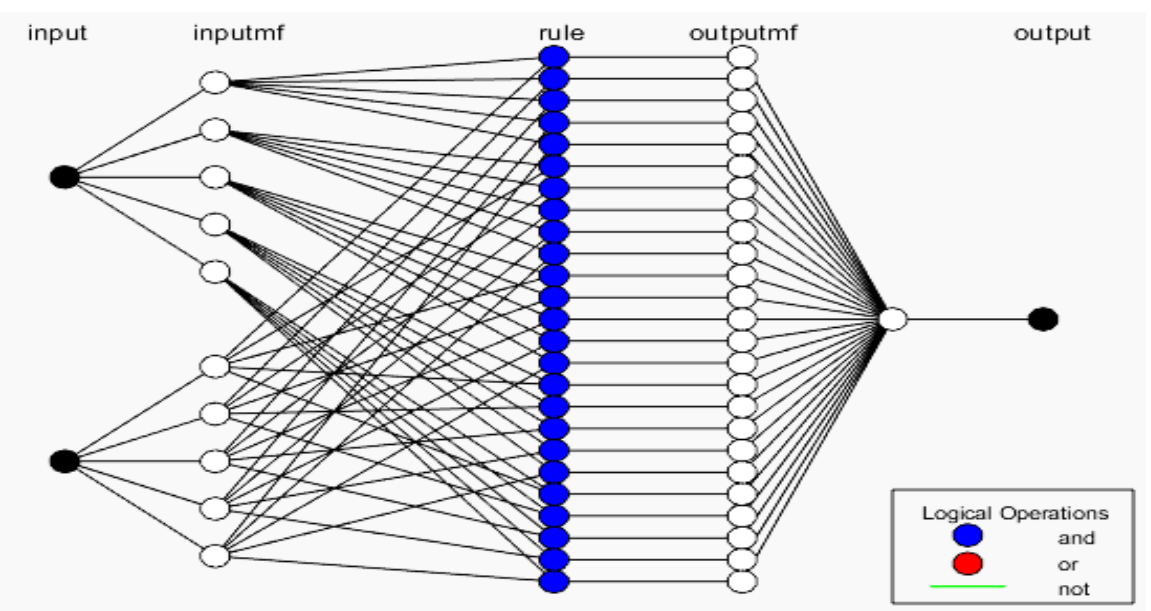

Figure 8. ANFIS structure for speed control of BLDC motor.

To keep the motor speed at a constant value of $3000 \mathrm{rpm}$ under different operating conditions, the ANFIS controller is used to compare PID and fuzzy controllers. The system performance with these controllers will be investigated through the speed, electromagnetic torque, rotor angle and stator currents waveforms in terms of dynamic performance indices, including steady-state error, maximum overshoot and settling time.

The motor is improved when applying the proposed ANFIS controller rather than using PID and Fuzzy controllers. ANFIS controller succeeded at eliminating the maximum overshoot while the other controllers were unable to eliminate it as depicted $n$ figure 9. Despite the success of the three controllers in keeping the speed constant at $3000 \mathrm{rpm}$, the ANFIS controller reached this speed in less time than the other two controllers.

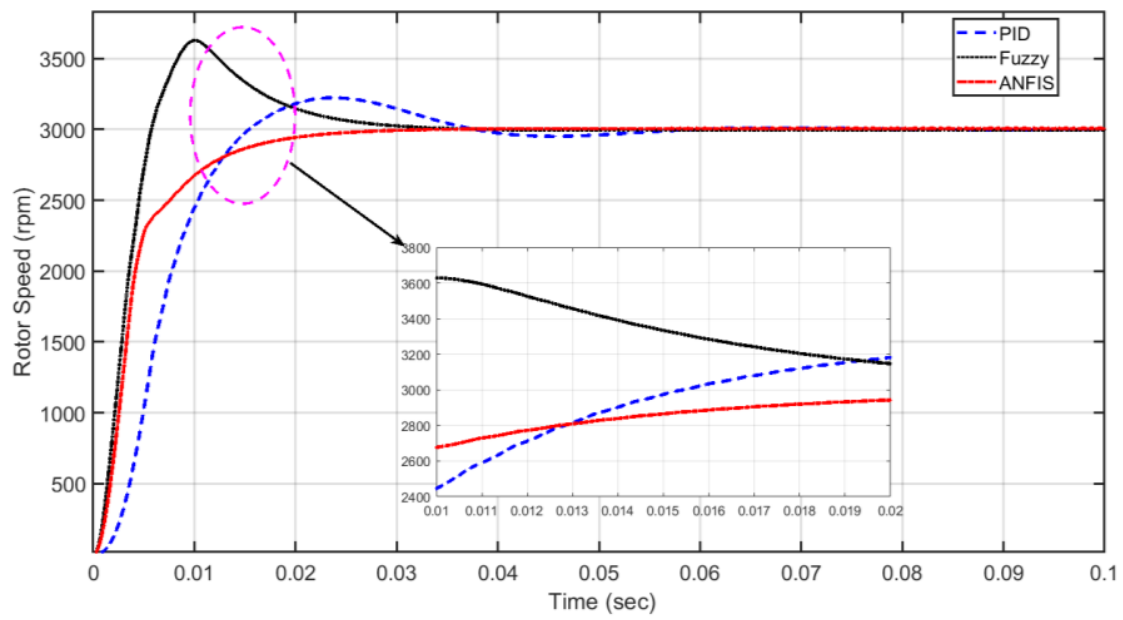

Figure 9. Speed response of BLDC Motor for all controllers.

The electromagnetic torque of the BLDC motor is examined with the three controllers. The best trend for this torque is obtained when using ANFIS controller in terms of maximum overshoot and settling time as in figure 10. It is worth saying that the BLDC motor will be converted from motor o generator mode as the sign of the electromagnetic torque is inverted when using PID and fuzzy controllers. While the ANFIS controllers succeeded at keeping the motor in the motor mode as no change in the electromagnetic torque, figure 10.

The rotor angle is plotted with the three controllers in figure 11 with the superiority of the ANFIS controller to PID and Fuzzy controllers. The maximum best profile for the stator current is obtained when applying ANFIS controller as in figure $12 \mathrm{a}, \mathrm{b}$ and $\mathrm{c}$. 


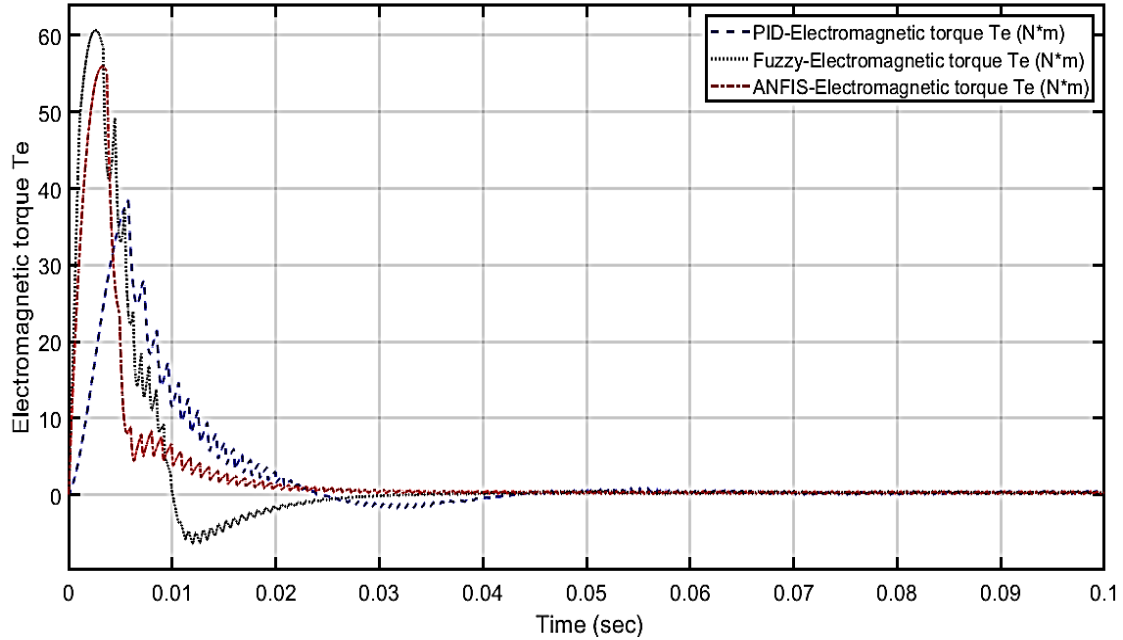

Figure. 10 Electromagnateic response of BLDC Motor for all controllers

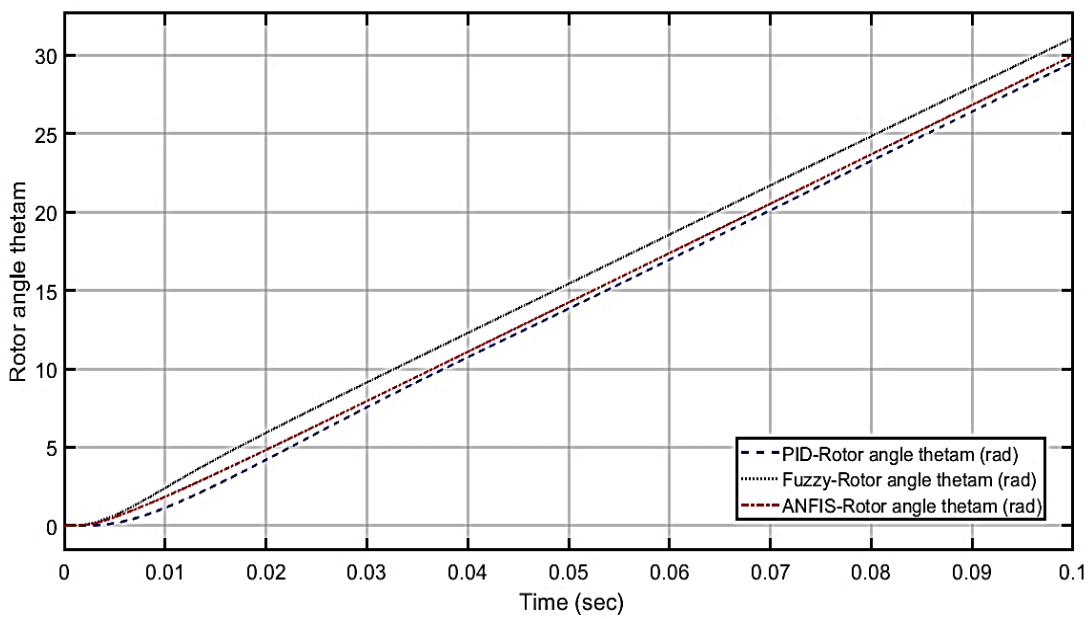

Figure. 11 Rotor angle response for all controllers.

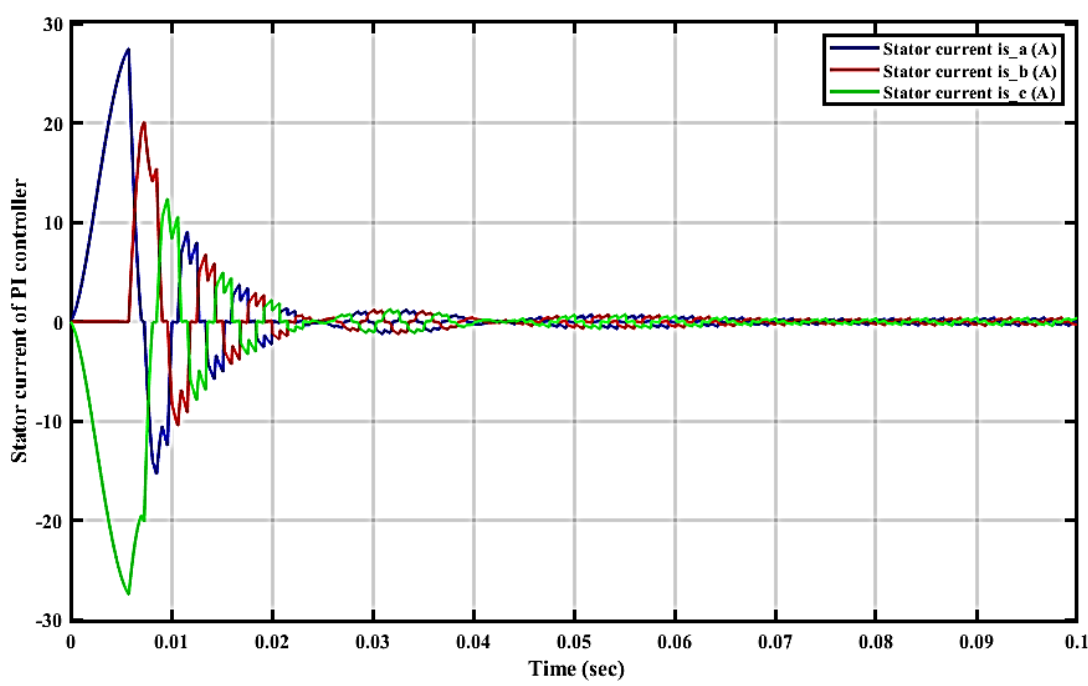

(a) 


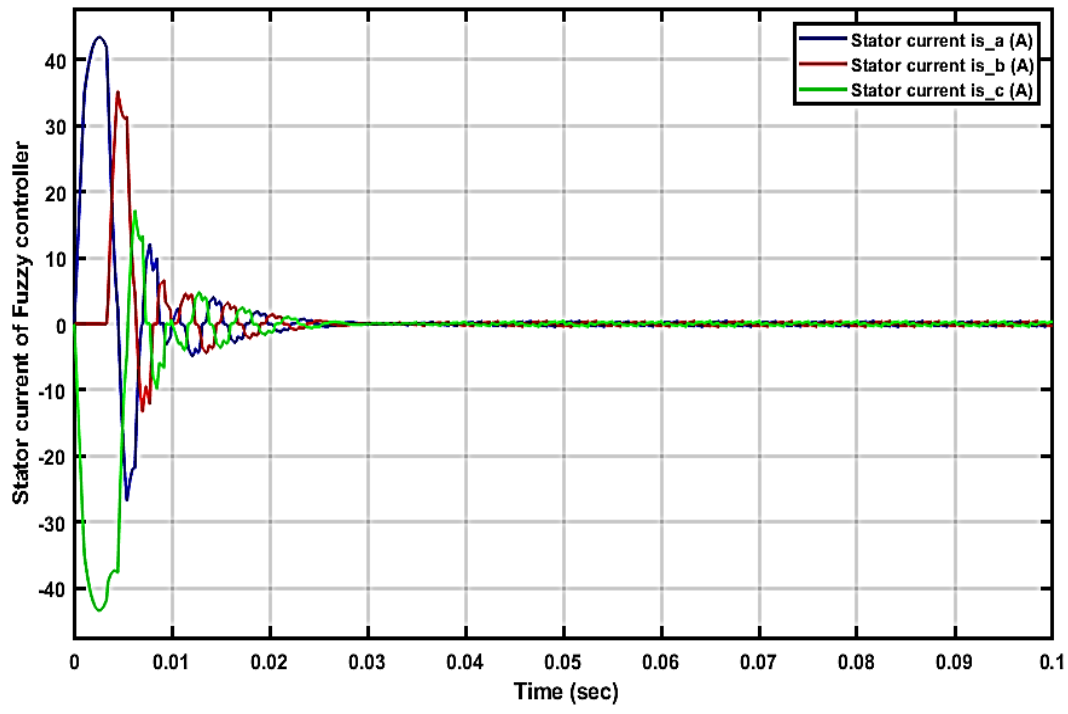

(b)

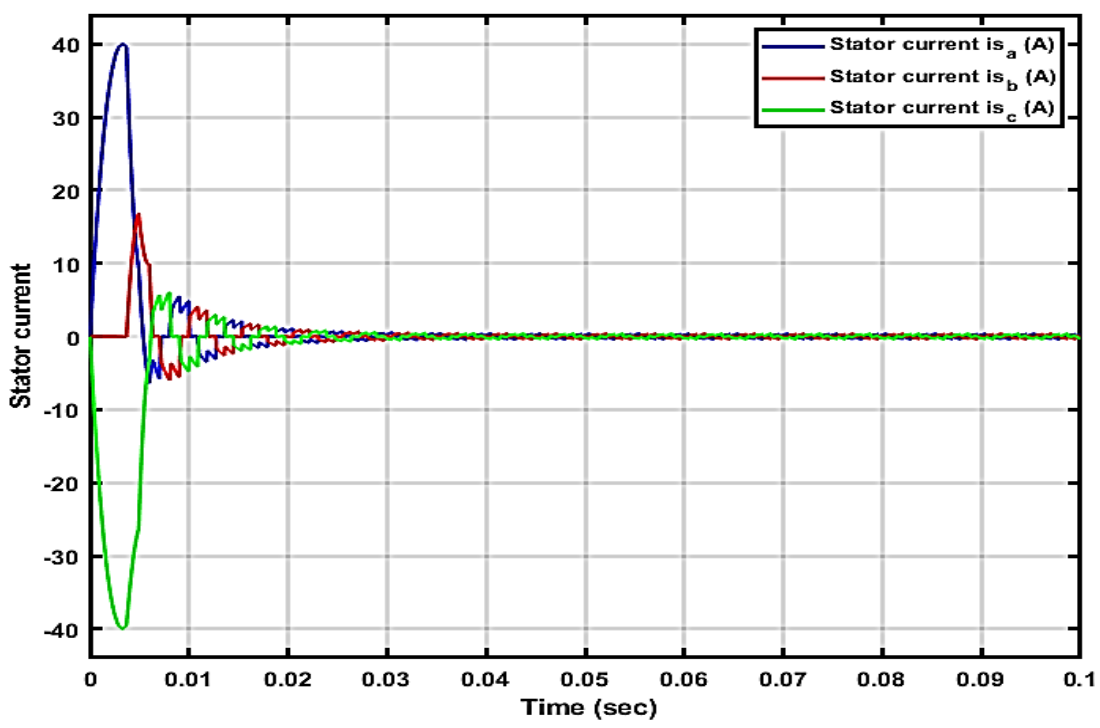

(c)

Figure. 12 Three-phase stator currents (a) PID controller (b) Fuzzy controller (c) ANFIS controller.

From these results, the robust stability for the Six-Step BLDC DC motor drive system using the proposed ANFIS controller. The Maximum overshoot and settling time values of speed and electromagnetic torque curves for PI, Fuzzy and ANFIS controllers are listed in Table 2. It is inferred that the ANFIS controller has high performance compared with PI and Fuzzy controllers from the above figures and statistics in Table 2, respectively.

Table 2. Comparative study for three controllers.

\begin{tabular}{cccc}
\hline State variable & PI & Fuzzy & ANFIS \\
\hline Max overshoot Speed & 0.0743 & 0.2091 & 0 \\
Settling time Speed & 0.0654 & 0.0412 & 0.0304 \\
Max overshoot (Te) & 0.383 & 0.6066 & 0.5574 \\
Settlingtime (Te) & 0.1 & 0.0392 & 0.0379 \\
\hline
\end{tabular}

\section{CONCLUSION}

This paper presents an ANFIS controller for speed control of BLDC motor along with comparisons with other controllers, PID and Fuzzy controllers. ANFIS controller proposed to improve the motor's performance by enhancing the speed, electromechanical torque, and stator current profiles. ANFIS controller succeeds at 
eliminating the overshot in the motor's speed. Also, the ANFIS controller could keep the motor in the motoring mode, while PID and Fuzzy could not keep the motor in the motoring mode.

Table 3. Brushless Dc Motor Parameters

\begin{tabular}{lc}
\hline \multicolumn{2}{c}{ Motor Parameters } \\
\hline Back electromagnetic force & Trapezoidal \\
Number of pole pairs, P & 4 \\
Rated Torque (Nm.) & 20 \\
Rated Speed (rpm) & 3000 \\
Rated Current (A) & 5 \\
Stator phase resistance Rs (ohm) & 2.8750 \\
Stator phase inductance Ls (H) & $8.5 * \mathrm{e}-3$ \\
Rotor inertia (gcm2) & $0.8 \mathrm{e}-3$ \\
Stator phase, star connections & 3 \\
Number of phases & 3 \\
\hline
\end{tabular}

\section{REFERENCES}

[1] Ahmed AM, Ali-Eldin A, Elksasy MS, Areed FF. Brushless DC motor speed control using both PI controller and fuzzy PI controller. International Journal of Computer Applications. 2015; 10(1) :29-35.

[2] Mosaad MI, El-Raouf MOA, Al-Ahmar MA, Bendary FM . Optimal PI controller of DVR to enhance the performance of hybrid power system feeding a remote area in Egypt. Sustain. Cities Soc. 2019; 47.

[3] Osama M, Mosaad MI, Al-Ahmar MA, Bendary FM . MPPT of Hybrid solar-wind-grid power generation system. Int. J. Industrial Electronics and Drives-Inderscience Publishers. 2015; 4(2); 234-241.

[4] ELhamed MA, Mosaad MI, Mohamed G,Abd El Aziz. Power Quality Improvement of WEGCS Using STATCOM Based EC Techniques. Int. J. of Industrial Electronics and Drives, Inderscience Publishers. 2017; 3(4);229 - 237.

[5] Mosaad MI, Fawzan Salem. Adaptive Voltage Regulation of Self Excited Induction Generator Using FACTS Controllers. Int. J. Industrial Electronics and Drives- Inderscience Publishers. 2014; 1(4); 219-226.

[6] Fawzan, Mosaad MI, awadallah M. A Comparative Study of MPC and Optimized PID Control. Int. J. Industrial Electronics and Drives-Inderscience Publishers. 2015; 2(4); 242-250.

[7] Mosaad MI, Alenany A, Abu-Siada A. Enhancing the performance of wind energy conversion systems using unified power flow controller. IN IET Generation, Transmission \& Distribution. 2019; 14(10); 1922-1929.

[8] Ajai KS, Ankit C, Ajay C, Ashish R, Rahul D. Fuzzy Logic Based Controllers for Speed Control of BLDC Motor. International Journal for Research in Applied Science \& Engineering Technology. 2017; 5.

[9] Kandiban R, and Arulmozhiyal R. Speed control of BLDC motor using adaptive fuzzy PID controller. International conference on Modeling, Optimization and computing, Elsevier. 2012; 306-313.

[10] Iyappan S, Vijayalakshmi M, Ramaprabha R. Analysis of Controllers for Speed Control in Brushless DC Motor Using MATLAB. International Journal of Emerging Technology and Advanced Engineering . 2014;4.

[11] Obed, Adel A, Abbas K, Kadhim. Speed and current limiting control strategies for BLDC motor drive system: A comparative study. International Journal of Advanced Engineering Research and Science. 2018; 2; 119-130.

[12] Behera, Muduli PK. Remote speed control of brushless DC motor with display. International Journal of Automation and Smart Technology. 2018; 8(2); 65-71.

[13] Zaid M,Sarwer Z,Ahmad F,Pandey M. Speed Control of PMBLDC Motor Using Fuzzy Logic Controller in Sensorless Mode with Back-EMF Detection. Applications of Artificial Intelligence Techniques in Engineering . 2018; 439-447.

[14] Sarojini DK, Dhanasekaran R. Improvement of Speed Control Performance in BLDC Motor Using Fuzzy PID Controller. Int. Conf. Adv. Commun. Control Comput. Technol. 2016; 1- 5.

[15] Kara. Brushless DC motor control under varying load conditions. Master's thesis, Izmir Institute of Technology, 2017.

[16] Premkumar, Manikandan. Adaptive Neuro Fuzzy Inference System based speed controller for brushless DC motor. Neurocomputing. 2014; 138.

[17] Anka RM. Torque control of BLDC Motor using ANFIS Controller. IJSRD. 2015;3.

[18] Monika T,Sankeswari S. Implementation and Performance Analysis of BLDC Motor Drive by PID, Fuzzy and ANFIS Controller. In addition to using ANFIS, the above work. 2017; 3.

[19] Pillay P, Krishnan R, Modeling, Simulation and analysis of PM motor drives part-1: the PM synchronous motor drive. IEEE Transactions on Industry Applications.1989;25(2); 265-273. 